(RESEARCH ARTICLE)

\title{
Knowledge and attitude on sexual and reproductive health among adolescents in Lalitpur, Nepal
}

\author{
Khanal Chitra 1, Gautam Saraswoti 2, Acharya Sharada 3, Pandey Laxmi ${ }^{4}$ and Mahara Gehendra 5, * \\ ${ }^{1}$ Policy, Planning and Monitoring Division, Ministry of Health and Population, Kathmandu, Nepal. \\ ${ }^{2}$ School of Nursing and Midwifery, Karnali Academy of Health Science, Jumla, Karnali, Nepal. \\ ${ }^{3}$ Bir Hospital Nursing Campus, National Academy of Health Science, Kathmandu, Nepal \\ ${ }^{4}$ National Centre for AIDS and STD Control, Department of Health Service, Ministry of Health and Population, \\ Kathmandu, Nepal \\ ${ }^{5}$ Department of Medical Statistics and Clinical Epidemiology, SYSU, Guangzhou, China.
}

Publication history: Received on 16 July 2020; revised on 29 July 2020; accepted on 30 July 2020

Article DOI: https://doi.org/10.30574/wjarr.2020.7.1.0267

\begin{abstract}
Adolescence is a very crucial period in which rapid physical, biological, emotional, and psychological changes occur. Therefore, adolescents need complete, accurate, and age-appropriate sexual and reproductive health information. This study was aimed to identify the knowledge and attitude on sexual and reproductive health among adolescents. It is a descriptive cross-sectional study carried out among 440 adolescents from four public schools of Lalitpur, Nepal. A structured Self-administrated questionnaire was applied to collect information. Descriptive and inferential statistics were employed to analyze the data. Out of 440 , more than half $(53.4 \%)$ of respondents had adequate knowledge on sexual and reproductive health with the mean age $17.76 \pm 8.74$ years. Adolescents who were studying grade 12 $(\mathrm{OR}=1.654, \mathrm{CI}: 1.126-2.429)$ had significantly higher knowledge than those of grade $11(\mathrm{p}=0.010)$. The majority $(85.9 \%)$ of adolescents had proper knowledge about the correct meaning of reproductive health. However, only $43.4 \%$ of respondents were aware that HIV/AIDS is not a curable disease. All most participants (87.3\%) agreed that men can have sex before marriage, and $73.1 \%$ disagree that women should not have sex before marriage. There was a significantly positive relationship between the knowledge and attitude of sexual and reproductive health $(p=0.000)$. This study established the adequate knowledge and positive attitude on sexual and reproductive health where the higher education of adolescents found a significant factor for the knowledge gaining on sexual and reproductive health. So, there needs to be sexual education in the school's curriculum, and this message should be disseminated through teaching, mass-media campaign, social network, and other effective platforms.
\end{abstract}

Keywords: Knowledge; Attitude; Sexual and reproductive health; Adolescents

\section{Introduction}

Adolescence is defined as the age of 10-19 years old [1]. About 1.2 billion people are adolescents, i.e 1 in 6 of the world's population, are adolescents [2]. In Nepal, $24 \%$ of the total population are adolescents [3]. Adolescence represents the major potential human resources for the overall development of any nation [4]. However, adolescence is the most challenging phase of life, in which every individual should face several consequences, such as physical, sexual, and social maturity [5].

An adolescent's sexual and reproductive health encompasses a significant element of the burden of sexual ill-health, where several health organizations are focusing on it to improve globally. Some of the challenges faced by adolescents across the world include early pregnancy and parenthood, difficulties accessing contraception and safe abortion, and high rates of HIV and sexually transmitted infections [6]. Sixteen million girls aged 15-19 give birth each year, which is

\footnotetext{
* Corresponding author: Dr. Gehendra Mahara
} 
approximately $11 \%$ of all deliveries worldwide, where $95 \%$ of these births occur in low and middle-income countries [2]. Adolescents often lack access to health information, counseling, legal protection, as well as health care and other social services [7]. Sexual and reproductive health among adolescents has emerged as an important issue in Asia [8]. Early marriage and early childbearing situation of Nepal is worse than any other south Asian region [9]. Forty percent of young women and twenty-four percent of young men had sex by age 18 years. Likewise, one-quarter of females and one-third of male youths age between 15-24 have comprehensive knowledge about AIDS, where only 38\% of women age 15-49 know that abortion is legal in Nepal [10]. Reproductive health education, as part of the school curriculum, will provide an effective means of improving knowledge and reducing reproductive health problems among adolescents in developing countries [11].

Most of the adolescents of remote areas have a lack of the basic knowledge about sexual health in Nepal and due to which they have been suffering from various sexual health-related issues [12]. Health workers and the teacher are reluctant to discuss the problems. Teaching-learning about sexual health is very poor in Nepal [13]. Most of the parents do not discuss sexual and reproductive health issues at home, so far, it is still considered taboo in many Nepalese societies. Therefore, adequate knowledge, guidance, and services are needed on reproductive and sexual health for school level adolescents in Nepal.

Moreover, various small and large-scale studies have been conducted on adolescent sexual and reproductive health in Nepal [14]. However, similar studies on sexual and reproductive health among school adolescents are very limited in Nepal. Thus, this study aimed to explore the current situation of knowledge and attitude on sexual and reproductive health among adolescents the public schools.

\section{Methods}

\subsection{Study design and setting}

A descriptive cross-sectional study was conducted to estimate the knowledge and attitude on sexual and reproductive health among adolescents studying in four Public Higher Secondary Schools of Lalitpur district, Nepal. Out of 39 schools, only four schools selected based on the lottery method. Adolescents studying at grade 11 and 12 aged between 16-19 years were the study population.

\subsection{Sample size calculation}

The sample size was estimated by assuming adolescents possess $0.5 \%$ knowledge and attitude on sexual and reproductive health, an error of $5 \%$ with a $95 \%$ confidence interval level, 0.06 allowable errors, non- response rate 12 percent, and cluster design effect 1.5. Therefore, the final sample size was 450 . The sample size when estimating a proportion: $n=Z^{2} \mathrm{pq} / \mathrm{l}^{2}$ (Cochran, 1977) formula. Where, $\mathrm{n}=$ the desired sample size, $\mathrm{z}=\mathrm{z}$ value $(1.96$ at $95 \%$ Confidence Limit), $\mathrm{p}=$ Prevalence of knowledge and attitude on sexual and reproductive health among adolescents $=0.5)$. Likewise, $\mathrm{q}=1-\mathrm{p}=1-0.5=0.5, \mathrm{l}=$ allowable error $( \pm 5 \%)=0.05$. In this study, absolute allowable error $=0.06, \mathrm{n}=$ $(1.96) 2 *(0.5) * 0.5 /(0.06) 2=267$. Adjusting $12 \%$ as non- response rate, sample size was: 300 . Considering the cluster design effect 1.5 , final sample was $300 * 1.5=450$. Finally, the cluster sampling technique was used to select the study participants based on similar characteristics of students.

The Knowledge about Sexual and Reproductive Health (ASRH) is a dependent variable, which is measured by using 57 questions. Each question contains " $0=$ incorrect or non- response" and $1=$ Yes" alternatives. As a result, the range score was $12-56$, and the participants who scored above the mean (the mean is 33.86 , and the standard deviation was 8.93 score) was considered as knowledgeable. Likewise, attitude towards ASRH was measured by using 16 attitudes related questionnaire. The participants who scored above the mean was considered a positive attitude less than mean was considered a negative attitude. Data was collected using structured self- administered questionnaire, which was first prepared in English then translated into Nepali for best understanding then translated back to English to maintain its consistency. The training was given to the data collectors and supervisors. The pre-test was done with 45 adolescents studying in Grade 11 and 12 at Namuna Higher Secondary School Lagankhel, Lalitpur, and any ambiguity, and missed points were incorporated in the final version of the questionnaire.

\subsection{Statistical analysis}

The overall data was collected and reviewed for completeness, accuracy, and consistency and entered in Excel sheet then transferred into Statistical Package for Social Science (SPSS) version 20.0 for further analysis. Normality was observed using the Shapiro Wilk test. Non- normally distributed data analyzed using the non-parametric test method. Descriptive statistics (frequency, percentage, range, mean and standard deviation) was used to describe the socio- 
demographic information. Chi-square and odds ratios were used to identify the significant differences ana association between the independent and dependent variables. Similarly, spearman's rank correlation was used to determine the relationship between the knowledge and attitude.

\section{Results}

A total of 450 adolescents, only 440, were included in the study (10 participants were discarded due to incomplete information). The mean age of adolescents was $17.76 \pm 8.74$ years.

Table 1 Socio- demographic Characteristics of Adolescents $(n=440)$

\begin{tabular}{|c|c|c|}
\hline Socio-demographic characteristics & Number & Percentage \\
\hline \multicolumn{3}{|l|}{ Age Group (age in years) } \\
\hline $16-17$ & 166 & 37.7 \\
\hline $18-19$ & 274 & 62.3 \\
\hline Mean \pm SD & $17.76 \pm 8.74$ & \\
\hline \multicolumn{3}{|l|}{ Sex } \\
\hline Female & 223 & 50.7 \\
\hline Male & 217 & 49.3 \\
\hline \multicolumn{3}{|l|}{ Residence } \\
\hline Urban & 325 & 73.9 \\
\hline Rural & 115 & 26.1 \\
\hline \multicolumn{3}{|l|}{ Grade } \\
\hline Grade -11 & 257 & 58.8 \\
\hline Grade -12 & 183 & 41.6 \\
\hline \multicolumn{3}{|l|}{ Stream } \\
\hline Management & 274 & 62.3 \\
\hline Education & 101 & 23.0 \\
\hline Humanities & 65 & 14.7 \\
\hline \multicolumn{3}{|l|}{ Religion } \\
\hline Hinduism & 297 & 67.5 \\
\hline Buddhism & 97 & 22 \\
\hline Christianity & 27 & 6.1 \\
\hline Islam & 19 & 4.3 \\
\hline \multicolumn{3}{|l|}{ Ethnicity } \\
\hline Janjati & 229 & 52.1 \\
\hline Brahaman/Chhetri & 166 & 37.7 \\
\hline Muslim & 19 & 4.3 \\
\hline Dalit & 19 & 4.3 \\
\hline Madhesi & 7 & 1.6 \\
\hline \multicolumn{3}{|l|}{ Socio-economic status } \\
\hline Sufficient for one year and surplus & 254 & 57.7 \\
\hline
\end{tabular}




\begin{tabular}{lll}
\hline Sufficient for less than one year & 121 & 27.5 \\
Sufficient for less than six months & 65 & 14.8 \\
Mother's education (n=440) & & \\
Literate & 249 & 56.6 \\
Illiterate & 191 & 43.4 \\
If literate, (n= 249) & & \\
Informal education & 108 & 43.4 \\
Primary level & 77 & 30.9 \\
Secondary level & 55 & 22.1 \\
Higher Secondary level & 7 & 2.8 \\
Graduate and above & 2 & 0.8 \\
Father's education (n= 440) & & \\
Literate & 360 & 81.8 \\
Illiterate & 80 & 18.2 \\
If literate, (n= 360) & & \\
Informal mal education & 88 & 24.4 \\
Primary level & 128 & 35.6 \\
Secondary level & 102 & 28.3 \\
Higher secondary level & 36 & 10 \\
Graduate and above & 6 & 1.7 \\
\hline
\end{tabular}

Table 1 shows $37.7 \%$ of adolescents were between the age of $16-17$ years, where $62.3 \%$ of were between the age of 18 19 years with mean age 17.76 and standard deviation 8.74 . Among them $50.7 \%$ were female and remaining $49.3 \%$ were male. Most (73.9\%) of the participants were from urban areas whereas only $26.1 \%$ were from rural area. More than half (58.8\%) of adolescents were studying grade 11 followed by $41.6 \%$ in grade 12 . This study found that $56.6 \%$ of adolescents' mothers were literate while $43.4 \%$ were illiterate. Only $5 \%$ had obtained higher education. Concerning the father's education, majority (81.8\%) of adolescents' fathers were literate and only $18.2 \%$ illiterate, however only $1.7 \%$ have had higher education.

Table 2 Level of knowledge of adolescents $(n=440)$

\begin{tabular}{lllll}
\hline Parameter & \multicolumn{2}{l}{ Level of the knowledge } & \multicolumn{2}{l}{ Level of Attitude } \\
\cline { 2 - 5 } & Number & Percentage & Number & Percentage \\
\hline Adequate knowledge & 235 & 53.4 & 421 & 95.7 \\
Inadequate knowledge & 205 & 46.6 & 19 & 4.3 \\
Total & 440 & 100 & 440 & 100 \\
\hline
\end{tabular}

Table 2 reveals that more than half (53.4\%) of adolescents had adequate knowledge about sexual and reproductive knowledge, while $46.6 \%$ of adolescents had inadequate with mean knowledge 33.86 and standard deviation of 8.93. The total knowledge score ranging was from 12 to 56 out of a total 57 score.

The attitude regarding reproductive and sexual health was found good such as the majority (95.7\%) of adolescents had positive attitude where as small proportion (4.3\%) of adolescents had negative attitude (mean and standard deviation of attitude score $3.6 \pm 0.3$ and ranges score was 2.1-4.6). 
Table 3 Association between knowledge level and socio-demographic characteristics of adolescents $(n=440)$

\begin{tabular}{|c|c|c|c|c|}
\hline \multirow[b]{2}{*}{ Variables } & \multicolumn{2}{|c|}{ Level of knowledge } & \multirow[b]{2}{*}{$p$-value } & \multirow[b]{2}{*}{ OR $(95 \% \mathrm{CI})$} \\
\hline & $\begin{array}{l}\text { Inadequate } \\
\text { n (\%) }\end{array}$ & $\begin{array}{c}\text { Adequate } \\
\text { n (\%) }\end{array}$ & & \\
\hline \multicolumn{5}{|l|}{ Age in years } \\
\hline $16-17$ & $87(52.4)$ & 79 (47.6) & & 1 \\
\hline $18-19$ & $118(43)$ & $156(56.9)$ & 0.057 & $1.456(0.988-2.144$ \\
\hline \multicolumn{5}{|l|}{ Sex } \\
\hline Female & $112(50.2)$ & $111(49.8)$ & \multirow[b]{2}{*}{0.121} & 1 \\
\hline Male & $93(42.9)$ & $124(57.1)$ & & $1.345(0.924-1.959$ \\
\hline \multicolumn{5}{|l|}{ Residence } \\
\hline Rural & $55(47.8)$ & $60(52.2)$ & & 1 \\
\hline Urban & $150(46.2)$ & $175(53.8)$ & 0.757 & $1.069(0.698-1.698$ \\
\hline \multicolumn{5}{|l|}{ Education level } \\
\hline Grade 11 & $133(51.8)$ & $124(48.2)$ & & 1 \\
\hline Grade 12 & $72(39.3)$ & $111(60.7)$ & $0.010^{*}$ & $1.654(1.126-2.429$ \\
\hline \multicolumn{5}{|l|}{ Stream } \\
\hline Education & $49(48.5)$ & $52(51.5)$ & & 1 \\
\hline Management and others & $156(46.0)$ & $183(54.0)$ & 0.659 & $1.104(0.708-1.724$ \\
\hline \multicolumn{5}{|l|}{ Religion } \\
\hline Non-hindu & $70(49.0)$ & $73(51.0)$ & 0.491 & 1 \\
\hline Hindu & $135(45.5)$ & $162(54.5)$ & & $1.150(0.771-1.715$ \\
\hline \multicolumn{5}{|l|}{ Ethnicity } \\
\hline Janjati & $102(48.3)$ & $109(51.7)$ & 0.480 & 1 \\
\hline Others & $103(45.0)$ & $126(55.0)$ & & $1.145(0.787-1.666)$ \\
\hline \multicolumn{5}{|l|}{ Mother's education } \\
\hline Illiterate & $95(49.7)$ & $96(50.3)$ & & 1 \\
\hline Literate & $110(44.2)$ & $139(55.8)$ & 0.246 & $1.25(0.856-1.824)$ \\
\hline \multicolumn{5}{|l|}{ Father's education } \\
\hline Illiterate & $40(50.0)$ & $40(50.0)$ & & 1 \\
\hline Literate & $165(45.8)$ & $195(54.2)$ & 0.499 & $1.182(0.725-1.919)$ \\
\hline \multicolumn{5}{|l|}{ Socio- economic status } \\
\hline \multicolumn{5}{|l|}{ Sufficient for } \\
\hline$>12$ month & $126(49.6)$ & $128(50.4)$ & & 1 \\
\hline$<12$ months & $79(42.5)$ & $107(57.5)$ & 0.138 & $1.333(0.910-6.578)$ \\
\hline
\end{tabular}

Table 3 shows the association between adolescents aged 18- 19 years (OR: 1.456, CI: 0.988-2.144) and knowledge on sexual and reproductive health, which was a significant positive correlation than those between the age of 18-19 years. Likewise, male adolescents (OR: 1.345, CI: 0.924-1.959) had more knowledge than female ( $p$-value $=0.121$ ), and adolescents who were studying grade $12(\mathrm{OR}=1.654, \mathrm{CI}: 1.126-2.429)$ were more knowledgeable in caparison to the 
grade 11 adolescents which was also statistically significant ( $p=0.010)$. However, there was no association observed between the level of knowledge with the stream, gender, and religion of adolescents. The result of this study also reveals that the adolescents who were other ethnic groups such as Brahman/ Chhetri, Dalit, Muslim (OR:1.145, CI: 0.787-1.666) had more knowledge than that of Janjati. However, it was not statistically significant $(\mathrm{p}=0.480)$.

Table 4 Association between the attitude and socio-demographic characteristics of adolescents $(n=440)$.

\begin{tabular}{|c|c|c|c|c|}
\hline \multirow{2}{*}{$\begin{array}{l}\text { Socio- } \\
\text { demographic } \\
\text { Characteristics }\end{array}$} & \multicolumn{2}{|l|}{ Level of attitude } & \multirow[b]{2}{*}{$P$-Value } & \multirow[b]{2}{*}{ OR $(95 \% \mathrm{CI})$} \\
\hline & $\begin{array}{l}\text { Negative attitude } \\
\text { n (\%) }\end{array}$ & $\begin{array}{c}\text { Positive Attitude } \\
\text { n (\%) }\end{array}$ & & \\
\hline \multicolumn{5}{|l|}{ Age in years } \\
\hline 16 to 17 & $9(5.4)$ & $157(94.6)$ & & 1 \\
\hline $18-19$ & $10(3.6)$ & $264(96.4)$ & 0.786 & $1.513(0.602-3.805)$ \\
\hline \multicolumn{5}{|l|}{ Sex } \\
\hline Female & $13(5.8)$ & $210(94.2)$ & & 1 \\
\hline Male & $6(2.8)$ & $211(97.2)$ & 0.114 & $2.177(0.812-5.836)$ \\
\hline \multicolumn{5}{|l|}{ Residence } \\
\hline Urban & $17(5.2)$ & $308(94.8)$ & & 1 \\
\hline Rural & $2(1.7)$ & $113(98.3)$ & $0.113^{\#}$ & $3.119(0.709-13.712)$ \\
\hline \multicolumn{5}{|l|}{ Education level } \\
\hline Grade 11 & $12(4.7)$ & $245(95.3)$ & & 1 \\
\hline Grade 12 & $7(3.8)$ & $176(96.2)$ & 0.668 & $1.231(0.475-3.191)$ \\
\hline \multicolumn{5}{|l|}{ Stream } \\
\hline $\begin{array}{l}\text { Management and } \\
\text { other streams }\end{array}$ & $15(4.4)$ & $324(95.6)$ & & 1 \\
\hline Education & $4(4.0)$ & $97(96.0)$ & $0.840^{\#}$ & $1.123(0.364-3.462)$ \\
\hline \multicolumn{5}{|l|}{ Religion } \\
\hline Non -Hindu & $7(4.9)$ & $136(95.1)$ & & 1 \\
\hline Hindu & $12(4.0)$ & $285(96.0)$ & 0.680 & $1.222(0.470-3.174)$ \\
\hline \multicolumn{5}{|l|}{ Ethnicity } \\
\hline Janjati & $11(5.2)$ & $200(94.8)$ & & 1 \\
\hline Others & $8(3.5)$ & $221(96.8)$ & 0.375 & $1.519(0.599-3.853)$ \\
\hline
\end{tabular}

\# Fisher's Exact Test, Pearson Chi-Square Test, $P$-value, $<0.05=$ significant, 1 : Reference

Table 4 characterizes the adolescents who were between the age of 18-19 years (OR: 1.513, CI: 0.602-3.805) had more positive attitude than those adolescents between the age of 16-17 years. However, it was not statistically significant $(p$ $=0.786)$. Likewise, the finding of this study revealed that male and grade twelves' adolescents had more positive attitude than female adolescents (OR:1.231, CI:0.475-3.191) and grade eleven (OR:1.231, CI:0.475-3.191). Similarly, there was no association experienced between attitude and other socio-demographic variables, such as stream, religion, ethnicity, and attitude of adolescents.

The positive correlation found between the knowledge and attitude of adolescents, which was statistically significant $(P=0.000)$ (Table 6). From this finding, it is confirmed that if a person knows sexual and reproductive health, then more prone to have a good attitude as well. 


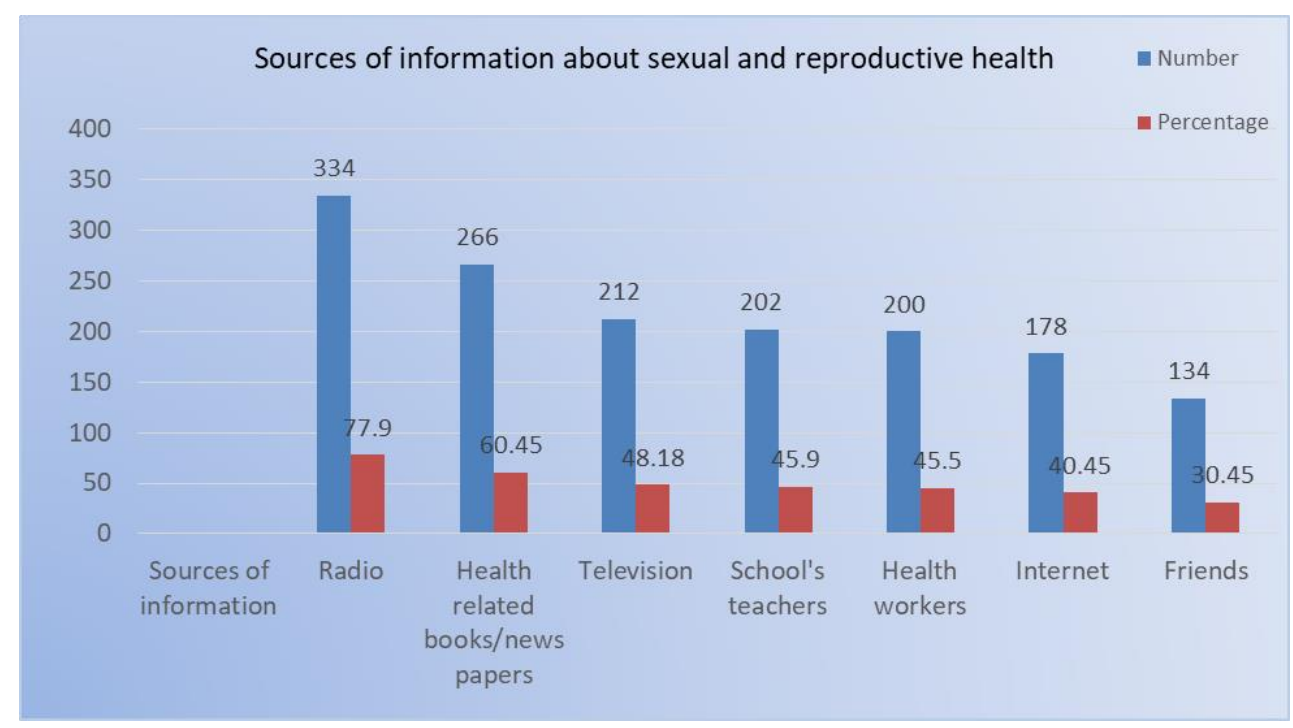

Figure 1 Source of sexual and reproductive health information

This study found that most of the participants were getting information regarding sexual and reproductive health through Radio followed by related books, news, TV, teachers, health workers, internet, and very less from friends. From this finding, we can conclude that students don't talk more about sexual and reproductive health frequently. Likewise, knowledge about adolescent and reproductive health on different elements also found satisfactory such as safe motherhood, safer sex, etc. (Supplementary file).

\section{Discussion}

The present study shows that more than half (53.4\%) of adolescents had adequate knowledge on sexual and reproductive health, which is consistent with the earlier study [15] that overall knowledge and the perception of adolescents on reproductive health was satisfactory. This study revealed that male adolescents had higher knowledge than females, which is contradictory with the finding of Sutan R [16] the mean knowledge score was (37.32 \pm 2.967$)$ with a significant difference for gender. The mean knowledge score was higher among females than that of males $(P=$ 0.000). Our study showed that the adolescents who were studying in grade 12 had more knowledge compared to the adolescents of grade $(p=<0.010)$. This finding is steady with the study Rahman, et al, [8] where senior students had significantly higher knowledge than the junior students about reproductive health $(p=<0.000)$.

The present study disclosed that urban adolescents had more knowledge of sexual and reproductive health in comparison to rural, although it was not statistically significant. Earlier findings support this finding [17]. All of those studies reported that rural youth had poor knowledge of sexual and reproductive health. Furthermore, $85.9 \%$ of adolescents knew the meaning of reproductive health, which is higher than the earlier study. In which only $29.4 \%$ of participants knew. The present study found that $62.6 \%$ of adolescents knew about safer sex, which differs from an earlier survey of Sah, et al, [12] where only $26 \%$ of respondents had proper knowledge about safer sex. $77.8 \%$ of adolescents had knowledge that the emergency contraception that can be taken within 72 hours of unprotected sex. This finding is quite higher than the outcome of the previous study [18]. Regarding the attitude on sexual and reproductive health, about $95.7 \%$ of adolescents had a positive perspective on sexual and reproductive health. There was no association found between the attitude and socio- demographical characteristics of respondents. Where, 87.3\%) of adolescents believed that men can have sex before marriage, and $71.3 \%$ of adolescents disagreed that women should not have sex before marriage. The present finding revealed that the majority of adolescents accept the premarital sex, i.e., $87.3 \%$ of respondents agreed with the statement "Men can have sex before marriage." which puts them vulnerable to sexually transmitted infections including HIV /AIDS. This is a great challenge for policymakers, stockholders, and academicians to incorporate safer sex education in the school's curriculum. A study [19] claimed that respondents' attitude towards premarital sex was moderate in an Iranian context where between 15\% and 27\% disagreed with prohibitions against premarital sex.

The present study shows that the majority (90.3\%) of adolescents agreed that school-based safer sex education is necessary for adolescents. This finding is similar to the outcome of an earlier study [20] reported that almost all students suggested having sex education which is necessary for youth before getting married. This study displayed that $77.9 \%$ 
of adolescents had used Radio to obtain information about sexual and reproductive health. This finding is a similarity with the study of Tegegn, et al, [21] where $80.4 \%$ obtained through Radio and $73 \%$ via TV. The positive correlation found between the knowledge and attitude of adolescents, which was statistically significant $(P=0.000)$.

The finding of the present study has limits in the generalization of findings because of small sample size and urban setting. The interventional study might have better assessed the knowledge and attitude on sexual and reproductive health among adolescents which the researcher could not do in the present study due to time and resources constrain.

\section{Conclusion}

This study concluded that adolescents have adequate knowledge and positive attitude on sexual and reproductive health. Higher education of adolescents is a significant factor for the knowledge of adolescents on sexual and reproductive health. However, there is no association between the attitude and socio-demographic characteristics of adolescents. In addition, there was a positive relationship between the knowledge and attitude on sexual and reproductive health among participants. Likewise, more than two-thirds of adolescents agreed on pre-marital sex or safer sex. So, it needs to be incorporated safer sex education in the school's curriculum and this message should be disseminated through teaching, mass-media campaign, and social network, and other effective platforms.

\section{Compliance with ethical standards}

\section{Acknowledgments}

The authors would like to thank all respondents for their willingness to participate in the study. We are also grateful to the ethical review board of Tribhuwan University, Institute of Medicine, Maharajgunj and District Education office of Lalitpur. Last but not least, we would like to show our gratitude to all the data collectors for their countless effort.

\section{Disclosure of conflict of interest}

There is no conflict of interest amongst the authors.

\section{Statement of ethical approval}

Ethical approval was obtained from the Institutional Review Board of Nursing Campus (IRB), Institute of Medicine of Tribhuwan University, Institute of Medicine Maharajgunj, Kathmandu, Nepal. Formal permission was obtained from the District Education Office and schools which were selected for study in the Lalitpur district. Individual written consent was also obtained from participants with a verbal explanation of the study, its purpose, and confidentiality.

\section{References}

[1] De Silva and Indralal W. (2012). Emerging reproductive health issues among adolescents in Asia. Boston, MA: Harvard School of Public Health, 139(617), 432-0686.

[2] Soltani H, Duxbury A, Rundle R and Marvin- Dowle k. (2017). Dietary habits and supplementation practices of young women during pregnancy: an online cross-sectional survey of young mothers and health care professionals. BMC nutrition, 3(1), 19.

[3] Paudel D, Ahmed M, Pradhan A and Dangol RL. (2013). Successful use of tablet personal computers and wireless technologies for the 2011 Nepal Demographic and Health Survey. Global Health: Science and Practice, 1(2), 277284.

[4] Patanwar P and Sharma KKN. (2013). Awareness of reproductive health among the kurmi adolescent girls of Raipur city, Chhattisgarh, India. International Journal of Research in Health Sciences, 1(13), 127.

[5] Rondini S and Krugu JK. (2009). Knowledge, attitude and practices study on reproductive health among secondary school students in Bolgatanga, upper east region, Ghana. African journal of reproductive health, 13(4).

[6] Morris JL and Rushwan H. (2015). Adolescent sexual and reproductive health: The global challenges. International Journal of Gynecology \& Obstetrics, 131, S40-S42.

[7] Seifu A, Fantahun M and Worku A. (2006). Reproductive health needs of out-of-school adolescents. A crosssectional. Ethiopian Journal of Health Development, 20(1), 10-17. 
[8] Rahman AA, Rahaman RA, Ibrahim MI, Salleh H, Ismail SB, Ali SH and Ahmad A. (2011). Knowledge of sexual and reproductive health among adolescents attending school in Kelantan, Malaysia. Southeast Asian Journal of Tropical Medicineand Public Health, 42(3), 717.

[9] Khatiwada N. (2013). Sexual and Reproductive Health of Adolescents and Youth in Nepal: Trends and Determinants: further analysis of the 2011 Nepal demographic and health survey. Ministry of Health and Population.

[10] Ministry of Health and Population (MOHP) [Nepal], New ERA, and ICF International Inc. (2012). Nepal Demographic and Health Survey 2011. Kathmandu, Nepal: Ministry of Health and Population, New ERA, and ICF International, Calverton, Maryland

[11] Mba CI, Obi SN and Ozumba BC. (2007). The impact of health education on reproductive health knowledge among adolescents in a rural Nigerian community. Journal of Obstetrics and Gynaecology, 27(5), 513-517.

[12] Sah RB, Ghimire A and Parajuli P. (2012). Knowledge and attitude on sexual behaviour among school adolescents. Health Renaissance, 10(3), 224-228.

[13] Regmi PR, Van Teijlingen E, Simkhada P and Acharya DR. (2010). Barriers to sexual health services for young people in Nepal. Journal of Health Population Nutrition, 28(6), 619-27.

[14] Denno DM, Hoopes AJ and V Chandra-Mouli V. (2015). Effective strategies to provide adolescent sexual and reproductive health services and to increase demand and community support. Journal of adolescent health, 56(1), S22-S41.

[15] Upadhyay-Dhungel K, Dhungel BA, Das PKL and Karki BMS. (2012). Perception and knowledge regarding reproductive health among adolescent males of Lalitpur. Asian Journal of Medical Sciences, 3(3), 27-31.

[16] Sutan R. (2014). Knowledge on Sexual and Reproductive Health among Adolescents in a College at Seremban, Negeri Sembilan. International Journal of Public Health Research, 4(2), 501-509.

[17] Regmi PR, Van Teijlingen E, Simkhada P and Acharya DR. (2010). Barriers to sexual health services for young people in Nepal. Journal of Health Population Nutrition, 28(6), 619-27.

[18] Nworah JO, Sunday UM, Joseph OU, Monday 00 and Josephat CA. (2010). Knowledge, attitude and practice of emergency contraception among students in tertiary schools in Anambra State Southeast Nigeria. International Journal of Medicine and Medical Sciences, 2(1), 001-004.

[19] Mohammadi MR, Mohammad K, Farahani FK, Alikhani S, Zare M, Tehrani FR and Alaeddini F. (2006). Reproductive knowledge, attitudes and behavior among adolescent males in Tehran, Iran. International Family Planning Perspectives, (32)1, 35-44.

[20] Regmi P, Simkhada P and Van Teijlingen E. (2008). Sexual and reproductive health status among young peoples in Nepal: opportunities and barriers for sexual health education and services utilization. Kathmandu University Medical Journal, 6(2), 1-5.

[21] Tegegn A, Yazachew M and Gelaw Y. (2008). Reproductive health knowledge and attitude among adolescents: a community based study in Jimma Town, Southwest Ethiopia. The Ethiopian Journal of Health Development (EJHD), 22(3), 143-51.

\section{How to cite this article}

Khanal C, Gautam BS, Acharya S, Pandey L, and Mahara G. (2020). Knowledge and attitude on sexual and reproductive health among adolescents in Lalitpur, Nepal. World Journal of Advanced Research and Reviews, 7(1), 282-290. 